\title{
Bincang Daring di Komunitas Tumbuh Sosial Sma Karangturi Semarang untuk Menumbuhkembangkan Minat dan Inovasi Siswa
}

\author{
Budi Sutedjo Dharma Oetomo \\ ${ }^{1}$ Program Studi Sistem Informasi, Fakultas Teknologi Informasi, Universitas Kristen Duta Wacana \\ Jl. Dr. Wahidin Sudirohusodo 5-25, Yogyakarta
}

\begin{abstract}
Abstrak - Untuk membuka tahun ajaran 2021/2022, SMA Karangturi Semarang telah menyelenggarakan bincangbincang secara daring bertema "Enhance Your Tech" dengan tujuan untuk menumbuhkan minat, dan memacu daya kreatif dan inovatif siswa dalam mempelajari teknologi terapan bidang Kecerdasan Buatan, khususnya Robotika, Teknologi Game, Data Science dan Digital Advertising. Kegiatan itu ditujukan untuk siswa kelas X-XII dan dihadiri guru serta seluruh pimpinan sekolah. Metode bincang-bincang daring memungkinkan peserta untuk berbincang langsung dengan para narasumber dari unsur akademisi, praktisi dan profesional perusahaan berskala nasional di tengah penerapan Pemberlakuan Pembatasan Kegiatan Masyarakat di masa pandemi Covid-19 ini. Sebelum mengikuti perbincangan itu, siswa dan guru telah melakukan persiapan dengan mendalami tema dan menyusun pertanyaanpertanyaan tertulis maupun lisan untuk menggali wawasan para narasumber. Pengetahuan dan terobosan-terobosan kreatif untuk membangun sinergi keilmuan dari matapelajaran-matapelajaran di sekolah yang diperoleh dari para narasumber akan didalami lebih lanjut dalam Komunitas Tumbuh Sosial. Kegiatan bincang-bincang secara daring tersebut telah menjadi sarana yang efektif dan efisien untuk mengembangkan wawasan, menemukan terobosanterobosan dan ide-ide kreatif dalam pembelajaran teknologi terapan dan kreatif bagi siswa, guru dan pimpinan sekolah.
\end{abstract}

Kata kunci-Belajar Kecerdasan Buatan, Bincang-bincang Daring, Komunitas Tumbuh Sosial, Minat dan Inovasi Siswa, Teknologi Terapan dan Kreatif.

Abstract - To open the 2021/2022 academic year, Karangturi Senior High School Semarang has held an online talk shows with the theme "Enhance Your Tech" with the aim of growing interest, and spurring students' creative and innovative power in studying applied technology in the field of Artificial Intelligence, especially Robotics, Game Technology, Data Science and Digital Advertising. The activity was intended for students in grades X-XII and was attended by teachers and all school leaders. The online talk shows method allows participants to have direct conversations with resource persons from academics, practitioners and professionals of national scale companies in the midst of the implementation of the Enforcement of Restrictions on Community Activities during the Covid-19 pandemic. Prior to participating in the discussion, students and teachers had made preparations by exploring the theme and compiling written and oral questions to explore the insights of the speakers. Knowledge and creative breakthroughs to build scientific synergies from school subjects obtained from resource persons will be further explored in the Social Growing Community. These online talk shows activities have become an effective and efficient means to develop insight, find breakthroughs and creative ideas in applied and creative technology learning for students, teachers and school leaders.

Keywords- Learning Artificial Intelligence, Online Talk Shows, Community Growing Social, Student Interest and Innovation, Applied and Creative Technology.

\section{PENDAHULUAN}

Dalam pembukaan tahun ajaran 2021/2022, SMA Karangturi Semarang menyelenggarakan Masa Orientasi Siswa (MOS) dalam bentuk baru yang disebut dengan Komunitas Tumbuh Sosial (KTS) [1]. Kegiatan yang bertema "Menerima diri sendiri, Bahagiapun menghampiri" tersebut merupakan bentuk kearifan civitas SMA Karangturi yang bertujuan membantu para siswa untuk mengenali lingkungan sekolah, menggali dan mengembangkan potensi-potensi dirinya, serta menumbuhkan jiwa-jiwa sosial yang saling berempati [2], sehingga mereka kelak siap menjadi pemimpin-pemimpin negeri dan pengusaha-pengusaha sukses di masa yang akan datang.

Dalam KTS tersebut, diselenggarakan berbagai kegiatan yang menarik perhatian siswa, karena pembelajaran tatap muka masih terbatas mengingat penerapan Pemberlakuan Pembatasan Kegiatan Masyarakat di masa pandemi Covid19 [3]. Salah satu diantaranya adalah sebuah webinar yang mempertemukan siswa kelas X-XII dengan seorang 
narasumber yang memiliki minat dalam pengembangan teknologi terapan dan kreatif. Acara itu dirancang untuk memberikan pengalaman bagi siswa dalam berinteraksi langsung dengan narasumber tamu yang akan memperluas wawasan tentang trend perkembangan teknologi terapan dan kreatif di masa yang akan datang. Bincang-bincang itu akan dimoderatori oleh guru pendamping. Sementara itu, para siswa tidak sekedar dimobilisasi untuk mengikuti webinar tersebut secara pasif, tetapi sejak sebelum kegiatan diselenggarakan, para siswa sudah diajak untuk memahami topik webinar dan merefleksikannya, lalu mereka menyusun bersama pertanyaan-pertanyaan untuk menggali lebih dalam pengetahuan dan pengalaman terapan dari narasumber [4]. Pertanyaan-pertanyaan akan diseleksi oleh guru pendamping sebelum diajukan kepada narasumber. Selanjutnya, hasil dari interaksi antara narasumber tamu dengan siswa itu akan dibahas dan didalami bersama para guru pendamping dalam KTS.
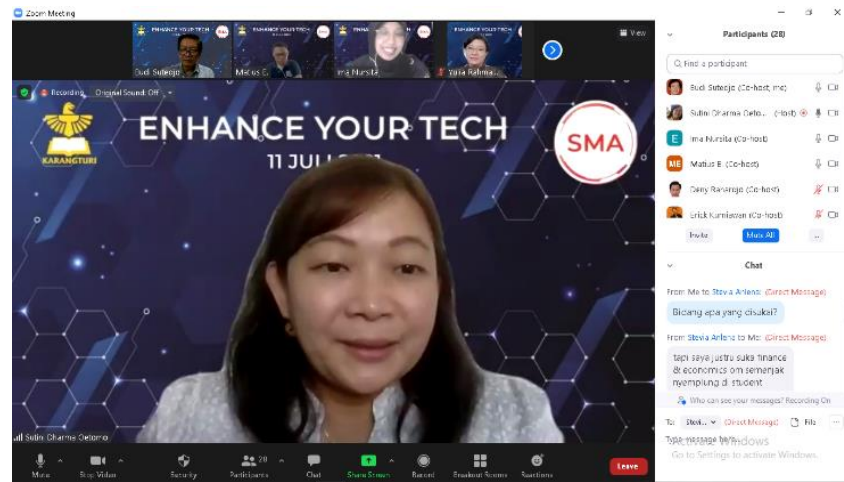

Gambar 1. Penggagas kegiatan bincang daring siswa bersama Budi Sutedjo sebagai narasumber tunggal

Kegiatan semula disiapkan oleh Sutini Dharma, S.Kom., M.Kom selaku guru Komputer di SMA Karangturi (Gambar 1) untuk mempertemukan para siswa dengan Budi Sutedjo Dharma Oetomo, S.Kom., MM sebagai narasumber tunggal yang merupakan alumni SMA Karangturi dan berprofesi sebagai dosen dan Ketua Senat Fakultas Teknologi Informasi UKDW. Budi Sutedjo memiliki pengalaman sebagai pemrakarsa Indonesia Menulis dan menjadi anggota Dewan Riset Daerah Daerah Istimewa Yogyakarta periode 2010-2020. Namun, rancangan itu berubah, ketika narasumber menawarkan keterlibatan para profesional dari perusahaan-perusahaan nasional terkemuka dan praktisi dalam acara itu, yaitu Dr. Deny Raharjo - Chief Information Officer for Indonesia and Rest of The World PT Asia Pulp and Paper Sinar Mas dan Dosen Pasca Sarjana Universitas Pelita Harapan, Matius Ekaprasetya, S.Kom - Senior Manager Project Development and Initiative PT Enseval Grup Kalbe Farma dan alumni Teknik Informatika UKDW, serta Erick Kurniawan, S.Kom. - Microsoft MPV, kandidat doktor (S3), Alumni dan Dosen Fakultas Teknologi Informasi UKDW.
Bertambahnya narasumber dalam kegiatan itu mendorong panitia melakukan perubahan konsep acara, khususnya dalam kepesertaan dan dinamika bincangbincang daring tersebut. Untuk kepesertaan, seluruh jajaran pimpinan sekolah dan guru ikut menghadiri acara tersebut. Moderator bincang-bincang daring itu dialihkan kepada seorang guru yang memiliki pengalaman memimpin seminar-seminar dengan skala nasional. Lalu, dibentuk tim panelis yang terdiri dari siswa dan guru untuk merumuskan pertanyaan-pertanyaan bagi para narasumber.

\section{PERMASALAHAN}

Di tengah situasi pandemi, dimana saat itu, kegiatan tatap muka masih dibatasi, maka sekolah harus berusaha mengemas masa orientasi sekolah dengan kegiatan yang menarik, memotivasi dan menginspirasi siswa. SMA Karangturi telah membuat kemasan baru dari masa orientasi sekolah, yaitu KTS. Namun, sekolah mengalami keterbatasan sumber belajar ahli yang memiliki wawasan luas, terobosan-terobosan dan ide-ide kreatif dalam pembelajaran teknologi terapan dan kreatif dalam bidang Kecerdasan Buatan, khususnya Robotika, Teknologi Game, Data Science dan Digital Advertising.

Keterbatasan relasi dengan sumber-sumber belajar yang menguasai bidang-bidang tersebut, khususnya para praktisi dan profesional berskala nasional sering menjadi kendala dalam mengembangkan kegiatan-kegiatan non kurikuler yang inspiratif bagi para siswa dan guru. Padahal, melalui pertemuan dengan para sumber belajar yang inspiratif, maka siswa akan menemukan visi yang memotivasi dan menggerakkan dirinya untuk belajar, sedangkan para guru dapat memperoleh terobosan-terobosan dalam menghubungkan matapelajaran dengan praktik sehari-hari sebagai ilmuwan, profesional dan usahawan.

Selain itu, guru dan pimpinan sekolah masih kurang informasi dan pengalaman tentang alasan, cara dan inspirasi untuk menciptakan kolaborasi antar jurusan dan minat ekstrakurikuler siswa, agar tercipta minat belajar dan kerjasama antar siswa. Seolah-olah setiap jurusan IPA dan IPS, serta pengembangan minat siswa yang diwadahi dalam kegiatan ekstrakurikuler saling terpisah satu dengan lainnya.

\section{METODE PELAKSANAAN}

Setelah dilakukan diskusi dan disetujuinya penambahan narasumber dalam kegiatan webinar dalam KTS tersebut, maka panitia mengubah konsep acara, menjadi:

A. Acara dilangsungkan pada hari Minggu, 11 Juli 2021, jam 11.00-13.00 WIB dalam bentuk webinar bincangbincang daring dan diberi tema "Enhance Your Tech". Acara tersebut dibagi dalam lima sesi dan dibuka secara langsung oleh kepala sekolah (Gambar 2 dan Gambar 3). Dalam sambutannya, Dr. Susena, M. Pd selaku kepala sekolah mengungkapkan nilai-nilai 
kearifan lokal SMA Karangturi yaitu: adaptif, responsif, inovatif dan fleksibel. Nilai-nilai itu mendasari siswa dan guru untuk tiada henti mengembangkan diri, memperluas wawasan global dan multibidang, menerapkan manajemen waktu dan memperluas relasi. Berlandaskan nilai-nilai itu pula, maka SMA Karangturi mengembangkan KTS, agar sejak dini para siswa dihantarkan untuk mampu mengenali potensi diri dan mengembangkannya untuk menyongsong keberhasilan di masa depan.

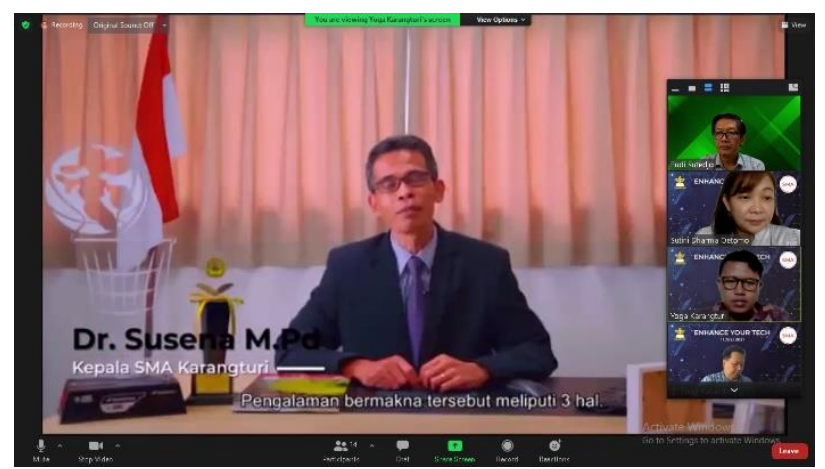

Gambar 2. Pembukaan webinar "Enhance Your Tech" oleh kepala sekolah

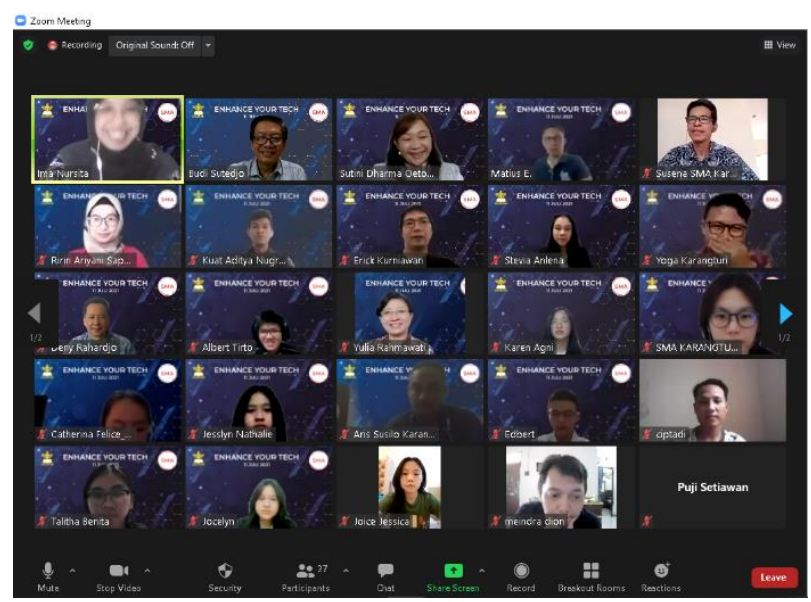

Gambar 3. Suasana webinar Enhance Your Tech

B. Pada sesi pertama, masing-masing narasumber diberi kesempatan mengungkapkan pandangan awal terkait dengan teknologi terapan dan kreatif dalam bidang Kecerdasan Buatan, khususnya Robotika, Teknologi Game, Data Science dan Digital Advertising yang dipandu dengan pertanyaan-pertanyaan yang telah dirumuskan panelis (Gambar 4).

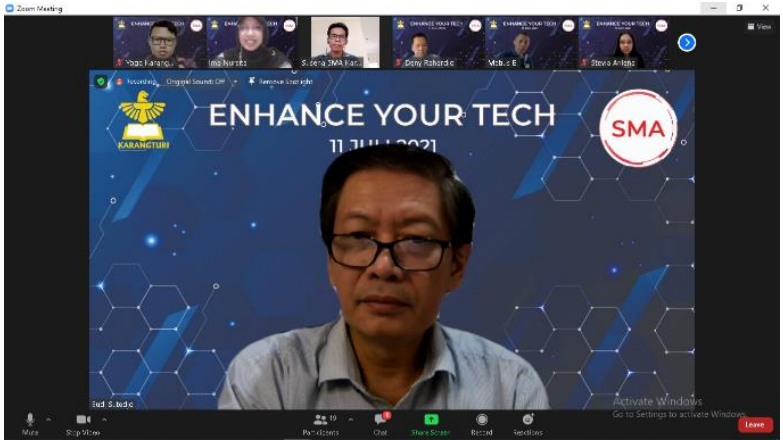

Gambar 4. Narasumber memberikan pandangan awal

C. Pada sesi kedua dan ketiga, dilakukan tanya jawab oleh moderator berdasarkan daftar pertanyaan dari panelis. Moderator memiliki kesempatan untuk mendalami dan mengkritisi jawaban narasumber. Tim panelis penyusun daftar pertanyaan terdiri dari para siswa yang mewakili angkatan, jurusan dan organisasi kesiswaan, serta guru pendamping. Pertanyaan-pertanyaan yang diajukan terkait dengan pengembangan dan penerapan teknologi terapan dan kreatif, khususnya terkait dengan bidang Kecerdasan Buatan [5], khususnya Robotika, Teknologi Game, Data Science dan Digital Advertising. Selain itu, pimpinan sekolah dan guru mempersiapkan pertanyaan untuk mendapatkan terobosan-terobosan kreatif dalam membangun sinergi keilmuan dari matapelajaran-matapelajaran di sekolah (Gambar 5).

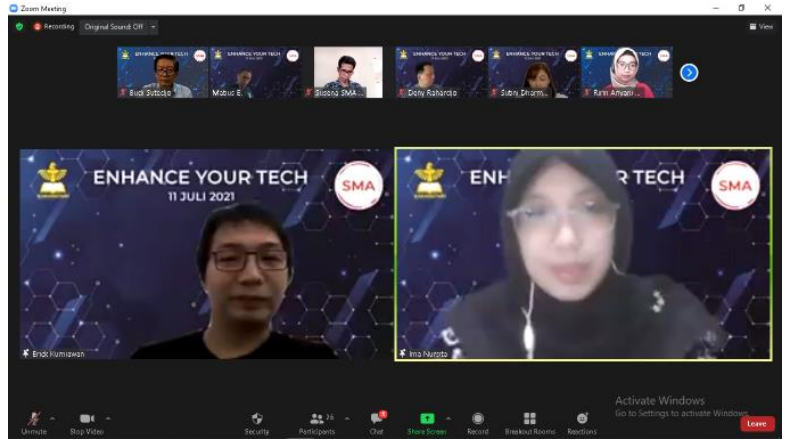

(a)

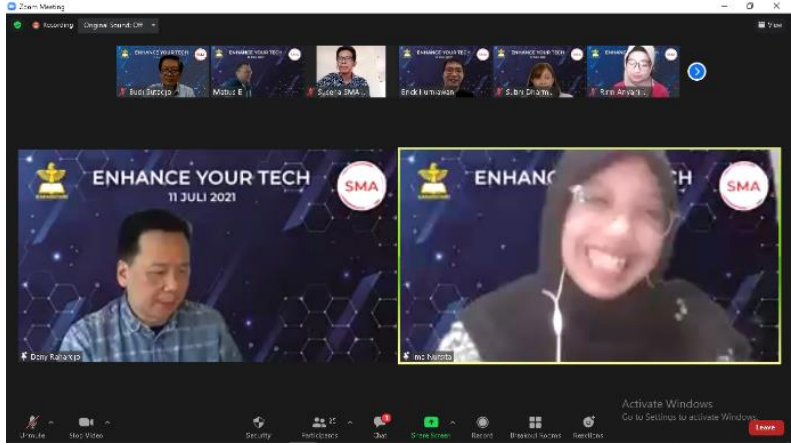

(b) 
Gambar 5. Tanya jawab dengan pertanyaan tertulis dipandu moderator

D. Pada sesi keempat, panitia membuka kesempatan tanya jawab lisan secara langsung yang terbuka bagi para siswa dan guru (Gambar 6 dan Gambar 7).
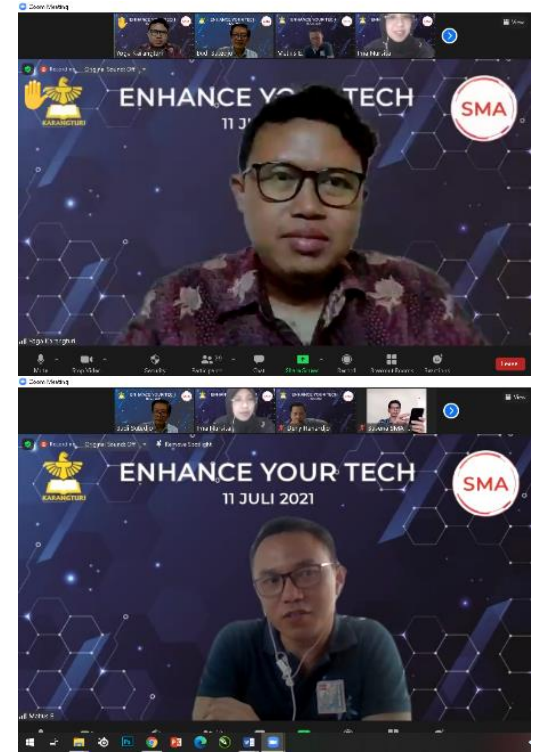

Gambar 6. Tanya jawab lisan antara guru dan narasumber
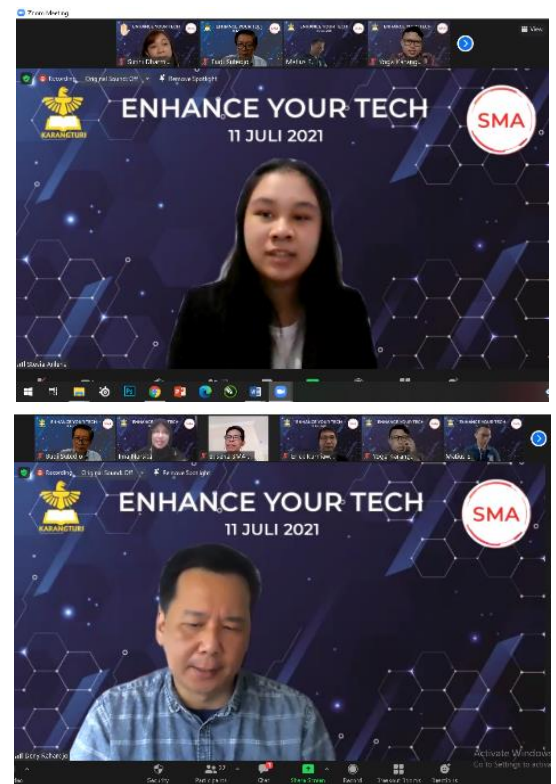

Gambar 7. Tanya jawab lisan antara siswa dan narasumber

Di sesi terakhir, para narasumber diberi kesempatan untuk memberikan pandangan akhir untuk memotivasi dan mendorong peserta dalam mendalami teknologi terapan dan kreatif sebelum acara ditutup oleh Yulia Rahmawati mewakili kepala SMA Karanturi. (gambar 8). Dalam sambutan penutupnya Yulia Rahmawati mengungkapkan bahwa banyak pengetahuan dan pengalaman para narasumber yang dapat dipetik dari acara tersebut, khususnya dalam menciptakan terobosan-terobosan untuk mengkaitkan keilmuan dan kegiatan-kegiatan yang dikembangkan di sekolah.

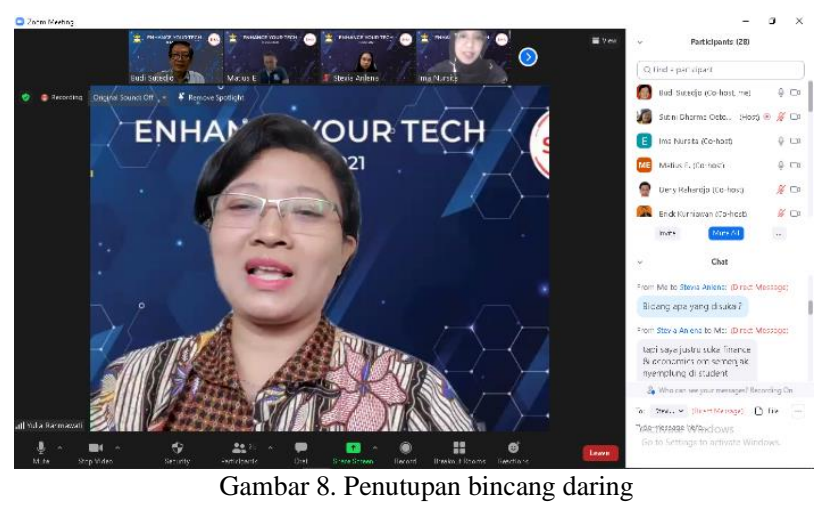

\section{HASIL DAN PEMBAHASAN}

Konsep MOS SMA Karangturi yang dikemas dalam bentuk KTS yang diisi antara lain dengan kegiatan bincangbincang daring antara siswa, guru, pimpinan sekolah dengan para narasumber dengan latar belakang akademisi, praktisi dan profesional dalam bentuk webinar dinilai efektif dan efisien, karena sekolah tidak terbebani dengan biaya transportasi dan akomodasi para narasumber, sehingga kegiatan serupa dapat terus dikembangkan di masa mendatang [6]. Perguruan tinggi dapat mendukung kegiatan tersebut dengan ikut menyiapkan narasumber dari latar belakang akademisi yaitu para dosen serta narasumber dari latar belakang praktisi dan profesional yaitu para alumninya. Konsep KTS itu membuka persepektif baru dalam hubungan perguruan tinggi, praktisi dan profesional dengan SMA sederajat. Dimana, para akademisi, praktisi dan profesional dapat ikut berpartisipasi untuk membangun visi ilmuwan, profesional dan usahawan dalam diri siswa sejak dini.

Pola persiapan untuk mengikuti webinar yang diajarkan oleh SMA Karangturi kepada para peserta dalam bentuk membuat daftar pertanyaan merupakan bentuk kearifan lokal atau strategi belajar yang efektif yang dapat dijadikan teladan[7]. Umumnya pada penyelenggaraan webinar, peserta mengikuti kegiatan itu secara pasif dan kurang persiapan. Pertanyaan-pertanyaan yang muncul pun sifatnya spontanitas pada saat peserta mendengar penjelasan narasumber. Namun, pola yang dikembangkan dalam KTS tersebut berbeda, dimana para siswa, guru dan pimpinan telah diajak untuk mengarahkan perhatian dan tertantang untuk mencari informasi tentang topik yang akan diperbincangkan sebelum mengikuti webinar. Pola bincangbincang daring KTS itu juga tetap memberikan ruang bagi peserta untuk bertanya secara lisan untuk mengakomodasi pertanyaan-pertanyaan yang muncul saat mendengarkan penjelasan para narasumber. 
Model persiapan itu tentu akan menumbuhkan keingintahuan dalam diri peserta tentang topik yang akan dibahas [8]. Pola persiapan itu juga mendorong para peserta untuk mengikuti webinar dari awal hingga akhir, karena mereka menanti pertanyaan-pertanyaannya dibahas dan keingintahuannya dipuaskan. Apalagi, mereka masih memiliki kesempatan untuk mengkritisi jawaban narasumber dalam sesi pertanyaan lisan.

Kualitas pertanyaan tertulis yang diajukan oleh peserta terkesan tidak asal-asalan. Pertanyaan-pertanyaan yang dirumuskan tergolong berkualitas dan berangkat dari keprihatinan atau keingintahuan peserta, bahkan pertanyaan berangkat dari persoalan yang mereka hadapi dalam pengembangan program ecopreneur[9]. Adapun bentuk pertanyaan yang diajukan, antara lain:

1. Seberapa pentingnyakah kita perlu mempelajari teknologi? Bagaimana teknologi kreatif itu dapat menjangkau masyarakat Indonesia di daerah minus?

2. Bagaimana cara kita dapat hidup bersama dengan teknologi yang canggih di masa depan tanpa mengurangi lapangan kerja yang ada? Bagaimanakah cara kita dapat bersaing di masa depan?

3. Mengapa teknologi kreatif ini seperti e-school, emoney, e-commerce dianggap sebagai solusi masa depan atau dianggap lebih baik dari pada sistem konvensional yang ada, sedangkan teknologi kreatif ini memiliki lebih banyak celah untuk dicurangi karena menggunakan suatu sistem dan tidak ada barang fisiknya?

4. Kami sebagai pebisnis mainan (SMA Karangturi mengembangkan Diamond Eagle Student Company yang memproduksi mainan dengan konsep ecopreneur) juga membuat aplikasi game yang bisa diunduh. Namun, kami sejujurnya penasaran, apakah teknologi game ini nantinya dapat digunakan dalam bidang lain selain entertain dan pendidikan?

5. Apakah digital advertising hanya bisa dilakukan oleh orang yang bekerja di sebuah perusahaan atau bisakah anak sekolahan juga melakukan digital advertising (seperti freelancer)?

Pola persiapan yang menghasilkan banyak pertanyaan dari peserta tersebut diimbangi dengan teknik moderasi acara yang sangat ketat dalam pengelolaan waktu, sehingga arah perbincangan tetap fokus pada topik dan seluruh pertanyaan tertulis yang telah disusun peserta dapat terjawab semua. Rata-rata masing-masing narasumber mendapatkan dua buah pertanyaan pada setiap sesinya.

Dalam perbincangan itu, para guru dan pimpinan sekolah juga mendapatkan inspirasi untuk mengkolaborasikan jurusan-jurusan yang dikembangkan di sekolah seperti IPA dan IPS, serta kegiatan-kegiatan kokurikuler sebagai bekal multidisiplin ilmu bagi para siswa[10]. Bahasan tentang kolaborasi multidisiplin ilmu, antara lain mengemuka dalam perbincangan tentang keterampilan yang perlu dimiliki seorang Digital Advertising. Dimana, seorang Digital Advertising membutuhkan penguasaan keterampilan dalam mengoperasikan perangkat-perangkat lunak yang biasanya tergolong dalam bidang IPA (Teknik Informatika atau Sistem Informasi), tetapi di sisi lain ia juga membutuhkan keterampilan untuk menyusun anggaran yang dapat dipelajari dalam bidang IPS (Ekonomi), keterampilan untuk pemilihan dan penyusunan kata dan kalimat yang dapat menggerakkan konsumen yang dapat dipelajari dalam matapelajaran Bahasa, serta ia juga membutuhkan pengetahuan dalam bidang Fotografi, Videografi, Musik dan Seni yang umumnya dapat dipelajari dalam kegiatan ekstrakurikuler. Informasi tersebut telah membuka wawasan para siswa dan guru tentang perlunya kolaborasi ilmu dan keterampilan multidisiplin ilmu, karena ilmu dan keterampilan itu saling menunjang untuk profesi-profesi baru di mana depan. Selain memotivasi siswa untuk mempelajari aneka ilmu dan keterampilan, informasi itu juga mendorong tumbuhnya kerjasama dan kolaborasi antar siswa dari beragam jurusan dan minat ektrakurikuler.

\section{KESIMPULAN}

Kegiatan bincang-bincang secara daring dalam KTS tersebut telah menjadi sarana yang efektif dan efisien untuk memberikan pengalaman interaksi antara peserta dengan akademisi, praktisi dan profesional berskala nasional, mengembangkan wawasan, menambah pengetahuan, membangkitkan visi peserta, serta menemukan terobosanterobosan dan ide-ide kreatif dalam pembelajaran teknologi terapan dan kreatif bagi siswa, guru dan pimpinan sekolah.

Pola persiapan peserta webinar berhasil membangkitkan keingintahuan dan antusias peserta terhadap topik yang akan dibahas sebagaimana tertuang dalam rumusan pertanyaan-pertanyaan yang diajukan kepada para narasumber dan keikutsertaannya dalam kegiatan itu dari awal hingga akhir.

Para guru dan pimpinan sekolah mendapatkan inspirasi untuk mengkolaborasikan jurusan-jurusan yang dikembangkan di sekolah seperti IPA dan IPS, serta kegiatan-kegiatan ko-kurikuler sebagai bekal multidisiplin ilmu bagi para siswa.

Kegiatan serupa dapat terus dibudayakan, agar dalam diri siswa tumbuh visi, motivasi dan inspirasi dari hasil pertemuan-pertemuan dengan para akademisi, praktisi dan profesional, sehingga mereka semakin bersemangat untuk belajar.

REFLEKSI KEGIATAN PKM 
Kegiatan PkM dalam bentuk bincang daring atau webinar tersebut sangat diperlukan untuk menumbuhkembangkan minat dan inovasi keilmuan siswa sejak mereka mengawali pembelajaran di jenjang SMA. Kegiatan tersebut memberi pengalaman bagi siswa SMA dalam berinteraksi langsung dengan akademisi, praktisi dan profesional, serta membangkitkan ketertarikan mereka pada bidang-bidang ilmu yang diperbincangkannya.

\section{UCAPAN TERIMA KASIH}

Penulis mengucapkan terima kasih yang sebesarbesarnya kepada Pimpinan SMA Karangturi Semarang yang telah menyelenggarakan kegiatan bincang daring "Enhance Your Tech" dan melibatkan penulis sebagai narasumber dan ikut ambil bagian dalam merancang kegiatan tersebut.

\section{DAFTAR PUSTAKA}

[1] Pramudia, J. R. (2006). Orientasi Baru Pendidikan: Perlunya Reorientasi Posisi Pendidik dan Peserta Didik. Jurnal Pendidikan Luar Sekolah, 29-39.

[2] Munadlir, A. (2016). Strategi Sekolah dalam Pendidikan Multikultural. Jurnal Pendidikan Sekolah Dasar, 114-128.

[3] Basar, A. M. (2021). Problematika Pembelajaran Jarak Jauh Pada Masa Pandemi Covid-19. Edunesia, 208-218.

[4] Mai, T., \& Ocriciano, M. (2017). Investigating the Influence of Webinar Participation on Professional Development of English Language Teachers in Rural Vietnam. Language Education in Asia, 48-66.

[5] Ciof, R., Travaglioni, M., Piscitelli, G., Petrillo, A., \& Felice, F. D. (2020). Artificial Intelligence and Machine Learning Applications in Smart Production: Progress, Trends, and Directions. Sustainability, 1-26.

[6] Mohalik, R., \& Poddar, S. (2020). Effectiveness of Webinars and Online Workshop During The Covid-19 Pandemic . SSRN, 1-13

[7] Chin, C., \& Osborne, J. (2008). Students' questions: a potential resource for teaching and learning science. Studies in Science Education, 1-39.

[8] Higgins, J., \& Moeed, A. (2017). Fostering Curiosity in Science Classrooms: Inquiring into Practice Using Cogenerative Dialoguing. Science Education International, 190-198

[9] Jebolise, E., \& Nwokocha, U. (2018). Sustainability-Oriented Practices of Eco-Innovation, Eco-Commitment and Organizational Performance of A Developing Economy. World Journal of Research and Review, 12-26.

[10] Laal, M., \& Ghodsi, S. M. (2012). Benefits of collaborative learning. Procedia - Social and Behavioral Sciences, 486 - 490. 